\title{
Cytological recognition of herpes simplex virus infection in bronchoscopic samples from the respiratory tract
}

\author{
${ }^{1}$ I Wilkinson, ${ }^{2} \mathrm{KS}$ Cuschieri, ${ }^{3} \mathrm{H}$ Monaghan, ${ }^{4} \mathrm{DM}$ Salter, ${ }^{5} \mathrm{WA}$ Wallace \\ ${ }^{1}$ Specialty Trainee in Pathology, Department of Pathology; ${ }^{2}$ Deputy Director, Scottish HPV Reference Laboratory, Department of Virology; \\ ${ }_{3,4,5}$ Consultant Pathologist, Department of Pathology, Royal Infirmary of Edinburgh, Edinburgh, UK
}

ABSTRACT Cytological features suggesting herpes simplex virus (HSV) infection in samples obtained at bronchoscopy have been described only very rarely in routinely processed samples. We report four cases where evidence of HSV infection was identified morphologically in samples processed using thin-layer techniques, with polymerase chain reaction confirmation of the presence of virus in three cases. We suggest that the increased morphological clarity provided by this technique for processing these cytology samples may result in the morphological features of viral infection being seen more frequently. Pathologists reporting such samples need to be aware of this possibility in order to avoid potential misinterpretations. In addition, however, respiratory and intensive care physicians unused to receiving cytology reports indicating 'HSV infection' need to be aware that the significance is uncertain and in most cases it is likely to indicate the reactivation of a latent infection.

Correspondence to WA Wallace, Department of Pathology, Royal Infirmary of Edinburgh, 54 Little France Crescent, Edinburgh EHI6 4SA, UK

tel. +44 (0) I3। 2427134

e-mail

william.wallace@luht.scot.nhs.uk

KEYWORDS Bronchial cytology, herpes simplex virus

DECLARATION OF INTERESTS No conflict of interests declared.

\section{CASE HISTORIES}

\section{Patient one}

An elderly patient was admitted directly to the intensive care unit with a diagnosis of community-acquired pneumonia (CAP) and sepsis. He was intubated and bronchial washings were obtained to investigate the underlying cause for the pneumonia. These were composed predominantly of neutrophils, macrophages and respira-tory epithelial cells with associated inflammatory debris. A population of scattered cells, some of which were multinucleated with nuclear clearing and occasional nuclear inclusions were identified, features highly suggestive of herpes simplex virus (HSV) infection (Figure I).

Of the sample, $200 \mu \mathrm{l}$ was subjected to nucleic acid extraction via the DNA Mini Kit (Qiagen Ltd, Crawley, UK). Briefly, this method involves enzymatic digestion using proteinase $\mathrm{K}$ and purification through silica columns. Deoxyribonucleic acid was eluted in $200 \mu \mathrm{l}$ of molecular grade water and stored at $-20^{\circ} \mathrm{C}$ pending polymerase chain reaction (PCR). A multiplex PCR was performed on the nucleic acid extracts using the method described by Aurelius et al., ${ }^{1,2}$ which identifies the GpD and GpG gene targets for HSV I and 2. Positivity was discerned by a band of the correct size being visualised via agarose gel electrophoresis - HSV I and 2 amplicon sizes being $10 \mathrm{I} \mathrm{nt}$ and $145 \mathrm{nt}$ respectively. The presence of HSV I was confirmed (Figure 2).

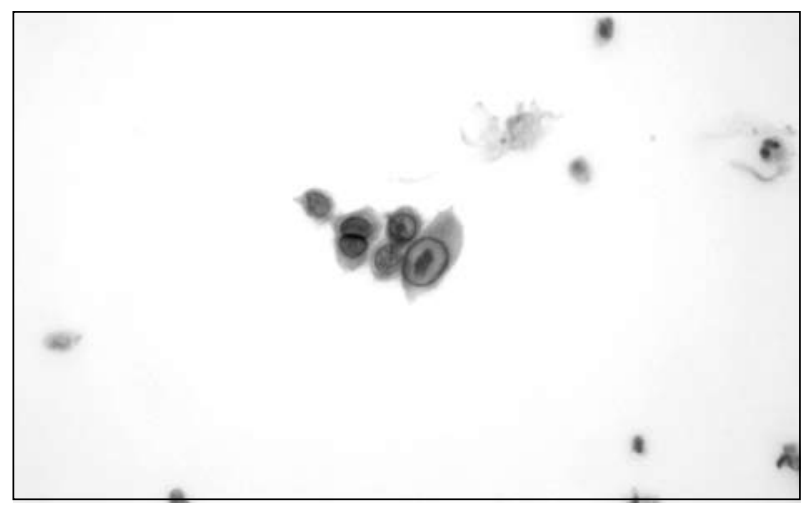

FIGURE I Photomicrograph of cells identified in bronchial washings showing features in keeping with herpes simplex infection. The nuclei are pale with a prominent, thick nuclear membrane (Papanicolaou stain, $\times 400$ original magnification).

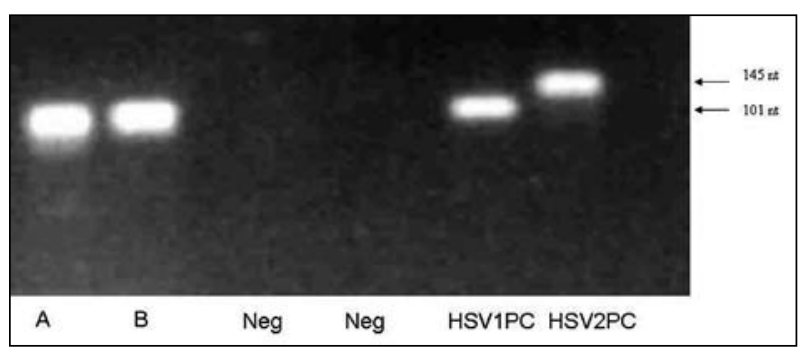

FIGURE 2 Photograph of PCR gel demonstrating positive bands in lanes $A$ and $B$ corresponding to the nucleic acid extracted from the bronchial washing samples. The size of the bands corresponds to that seen for the HSV I positive control $(\mathrm{IOI} \mathrm{nt})$. (A and B:PCR amplicons generated from nucleic acid extracted from bronchial washing sample; Neg: negative amplification controls; HSVIPC: positive amplification control for HSVI; HSV2PC: positive amplification control for HSV2.) 


\section{Patient two}

An elderly patient who was a heavy smoker with a known history of chronic obstructive pulmonary disease was admitted with increased shortness of breath. At bronchoscopy, a lesion was identified in the left upper lobe and bronchial washings as well as a single bronchial biopsy were obtained. A tissue diagnosis of squamous cell carcinoma was made on the biopsy specimen. The bronchial washings specimen was composed of neutrophils and inflammatory debris with a small number of respiratory epithelial cells and alveolar macrophages. Several clusters of dyskeratotic, cytologically atypical cells were seen which were regarded as being suspicious of squamous cell carcinoma. In addition, groups of respiratory epithelial cells showing features suggestive of infection with HSV were identified. Polymerase chain reaction confirmed the presence of HSV I.

\section{Patient three}

A middle-aged patient was admitted directly to the intensive care unit with severe CAP. A tracheostomy was subsequently performed and bronchial washings were obtained. The bronchial washings contained numerous respiratory epithelial cells and alveolar macrophages as well as clusters of cells showing features suggestive of HSV. Polymerase chain reaction confirmed the presence of HSV I.

\section{Patient four}

An elderly patient was admitted with CAP, opiate toxicity and renal failure. Subsequently the patient developed obstructive bowel symptoms and underwent a laparotomy. Following surgery the patient continued to suffer from respiratory symptoms and underwent a bronchoalveolar lavage. Around this point it was noted that the patient had developed perioral cold sores. Morphologically, cells showing features in keeping with HSV infection were identified in the lavage fluid. Polymerase chain reaction was not performed.

\section{DISCUSSION}

Fibreoptic bronchoscopy is frequently performed in patients with abnormal chest radiology where there is a suspicion of pneumonia or malignancy. ${ }^{3}$ Even when the samples are primarily obtained for microbiological investigations they are also frequently submitted for cytological examination. In these cases the cytological features are rarely specific for any particular organism. ${ }^{4}$ Changes in sample processing in diagnostic pathology laboratories may lead to new diagnostic challenges and opportunities. This has already been demonstrated in gynaecological cytology, where the move away from traditional smears to liquid-based cytology has resulted in a change in the diagnostic spectrum, with an increase in the detection of infections such as HSV. ${ }^{5}$ This is predominantly due to the greater preservation of cytological features seen in liquid-based cytology.
Over recent years this processing technique has been increasingly used in diagnostic cytopathology including those samples generated from the respiratory tract. ${ }^{6,7}$ We report four cases where cells with the cytological features of HSV were observed in bronchial cytology samples processed using this method. Detection of HSV infection in traditionally processed respiratory specimens is rare, ${ }^{8}$ but given the improved cellular morphology seen with thin-layer processing, detection may become more common.

Over the two-year period these cases were collected, 4I3 bronchial washings samples were submitted from units within the Royal Infirmary of Edinburgh, of which 18 were from the general intensive care unit. This suggests that only a small proportion of samples taken from patients in intensive care are being submitted for cytological examination. The fact that in three of these 18 cases HSV-infected cells were identified supports the hypothesis that new processing techniques may lead to an increased chance of morphological detection of HSV infection. In addition, our cases demonstrate that routinely collected and stored cytology specimens can be used for PCR to confirm the presence of HSV when this is cytologically identified, without the need for further samples being obtained in cases where material has not been submitted for virological investigations.

The diagnosis of HSV is possible due to a series of welldescribed characteristic cellular changes. Infected cells typically become multinucleated, with swollen nuclei clustered tightly together leading to a characteristic moulding of nuclear contours. The presence of viral inclusions results in a loss of chromatin pattern and the nuclei are seen to take on an empty homogenised or 'ground glass' appearance with a prominent nuclear membrane: these are known as Cowdry type B nuclei. ${ }^{4,5}$ Later in the infective process, strongly eosinophilic inclusions develop in the nucleus known as Cowdry type A inclusions, which are often wedge-shaped or triangular and can appear refractile.

Several potential misdiagnoses exist, the most common being mistaking the changes as those of cytomegalovirus, but perhaps more importantly the cells may be misinterpreted as being malignant, particularly if a necrotic and degenerate background exists. ${ }^{8}$ In the presence of atypical keratinising cells the possibility of squamous carcinoma may be suggested or the atypical cells may be mistaken for well-differentiated adenocarcinoma cells as they may show features reminiscent of that seen in bronchoalveolar carcinoma. ${ }^{4,8}$

While pathologists reporting respiratory cytology samples need to be aware of the possibility of HSV infection and its potential for misinterpretation and misdiagnosis, so do those who will receive the final report. The clinical significance of detecting evidence of 
HSV in patients presenting with pneumonia remains controversial.9 It is likely that in most patients it represents evidence of reactivation of latent HSV infection rather than evidence of a true viral pneumonitis. Studies in ventilated patients with pneumonia have shown a high incidence of PCR-detectable HSV in respiratory samples and it is unclear whether there is any specific benefit in initiating treatment in the absence of other features to suggest a true viral pneumonitis. Similarly, in patients with underlying malignancy this is likely to represent reactivation as this has been shown to be common in cancer patients. ${ }^{10}$ The possibility of a true viral pneumonitis will, however, merit more consideration in patients in high-risk caterories such as those on immunosuppressive therapy following transplantation or undergoing chemotherapy for malignancy.

\section{CONCLUSION}

Changes in laboratory practices can change the spectrum of abnormalities identifiable in specimens submitted to pathology departments. While an awareness of the features of HSV infection in bronchial cytology samples and the potential for misdiagnosis needs to be borne in mind by pathologists, physicians requesting cytological examinations also need to be aware so that bronchial cytology reports describing 'HSV infection' are not overinterpreted.

\section{REFERENCES}

I Aurelius E, Johansson B, Sköldenberg B. Encephalitis in immunocompetent patients due to herpes simpex virus type I or 2 as determined by type-specific polymerase chain reaction and antibody assays of cerebrospinal fluid. J Med Virol 1993; 39:I79-86. doi: I0.1002/jmv. I890390302

2 Aurelius E, Johansson B, Sköldenberg B et al. Rapid diagnosis of herpes simplex encephalitis by nested polymerase chain reaction assay of cerebrospinal fluid. Lancet 1991; 337:189-92. doi:10.1016/0140-6736(9I)92I55-U

3 Kaparianos A, Argyropoulou E, Sampsonas F et al. Indications, results and complications of flexible fibreoptic bronchoscopy: a 5 -year experience in a referral population in Greece. Eur Rev Med Pharmacol Sci 2008; 12:355-63.

4 Gray W. Normal respiratory tract and inflammatory conditions. In: Gray W, McKee GT, editors. Diagnostic cytopathology. 2nd ed. London: Churchill Livingstone; 2003. p. I7-70.

5 Aslan DL, Pambuccian SE, Prekker FL et al. Accuracy of herpes simplex virus detection in liquid-based (SurePath) Papanicolaou test: a comparison with polymerase chain reaction. Diagn Cytopathol 2008; 36:94-103. doi:10.1002/dc.20732
6 Wang HH, Sovie S, Trawinski G et al. ThinPrep processing of endoscopic brushing specimens. Am J Clin Pathol 1996; 105: I63-7.

7 Wallace WA. Changing roles for histology and cytology in the management of patients with lung carcinoma. J $R$ Coll Physicians Edinb 2008; 38:292-7.

8 Lapkus O, Elsheikh TM, Ujevich BA et al. Pitfalls in the diagnosis of herpes simplex infection in respiratory cytology. Acta Cytologica 2006; 50:617-20.

9 Simoons-Smit AM, Kraan EM, Beishuizen A et al. Herpes simplex virus type $I$ and respiratory disease in critically-ill patients: real pathogen or innocent bystander? Clin Microbiol Infect 2006; I2:1050-9. doi:I0.IIII/j.|469-069I.2006.0I475.x

10 Djuric M, Jankovic L, Jovanovic T et al. Prevalence of oral herpes simplex virus reactivation in cancer patients: a comparison of different techniques of viral detection. J Oral Pathol Med 2009; 38: 167-73.

\section{CONFERENCING AND EVENTS}

The Royal College of Physicians of Edinburgh has a unique blend of rooms providing the perfect location for your conference, meeting or event. The Victorian Great Hall, galleried New Library and the Georgian Cullen Suite are wonderful settings for dinners and receptions. The modern Conference Centre seats up to 300 people in raked seating and is complemented by breakout rooms seating from 10 to 150 people, a keypad voting system and video conferencing. The College provides a stunning setting for weddings and receptions and is licensed for both civil and religious ceremonies. Discounts are available for Fellows and Members, medical conferences and charities.

For more information or for a quotation, please contact the Events Team on +44 (0) I 3 I 225 7324; email events@rcpe.ac.uk or visit http://www.rcpe.ac.uk/conferencing/index.php

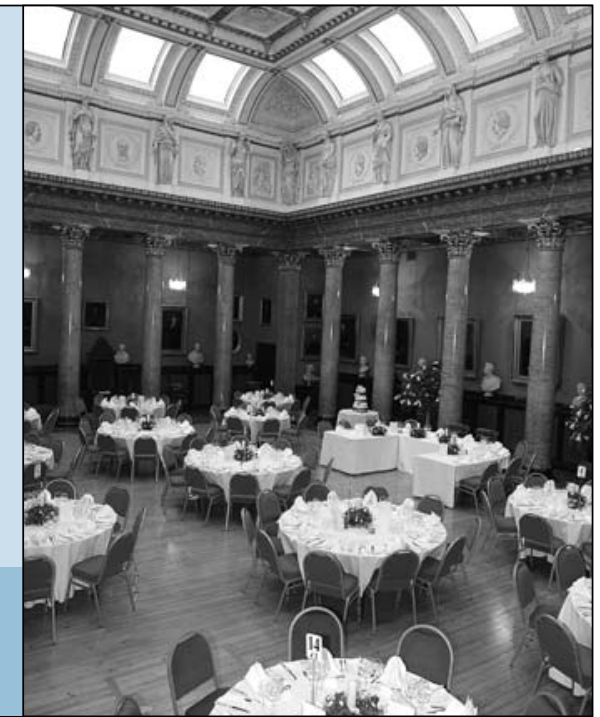

